\title{
REALIDADE DA GESTÃO DA QUALIDADE NOS LATICÍNIOS DE MICRO E PEQUENO PORTE DA REGIÃO DOS CAMPOS GERAIS - PARANÁ
}

\author{
Tiago Henrique de Paula Alvarenga ${ }^{1}$ \\ Juliana Vitória Messias Bittencourt² \\ Carlos Manuel Taboada Rodriguez ${ }^{3}$
}

\begin{abstract}
RESUMO
O presente trabalho tem como objetivo descrever a realidade da gestão da qualidade nos laticínios de micro e pequeno porte da região dos Campos Gerais no Paraná. Foram pesquisadas dez das treze empresas da população de laticínios da região. A metodologia utilizada foi o levantamento, na qual se empregou a aplicação de um questionário semiestruturado. O presente estudo conseguiu caracterizar a realidade da gestão da qualidade nos laticínios pesquisados através das "Eras" da Qualidade elaboradas por Garvin (2002). Foi detectado que tais laticínios estão direcionados para uma gestão voltada para a garantia da qualidade dos produtos, sendo detectada ausência de ações estratégicas que torne os laticínios robustos, principalmente em relação ao Mercado Comum do Sul (MERCOSUL).
\end{abstract}

Palavras-chave: controle da qualidade, eras da qualidade, gestão da qualidade, laticínios, qualidade.

\section{QUALITY MANAGEMENT REALITY IN THE SMALL DAIRIES OF CAMPOS GERAIS' REGION - PARANÁ}

\begin{abstract}
This paper aims to describe the reality of quality management in micro and small dairy industry of the region of Campos Gerais in Paraná State. Ten of the thirteen dairy industry of that area was analyzed. The methodology we used was a survey, by the employment of a semi-structured questionnaire. The present study was able to characterize the reality of quality management in the dairies searched through the "Ages" of the Quality produced by Garvin (2002). It was discovered that such dairies are targeted for management aimed at ensuring product quality. However this dairies has a lack of strategic action which would make them stronger especially in relation to the Southern Common Market (MERCOSUL).
\end{abstract}

Keywords: eras of quality, dairy, quality, quality control, quality management.

\footnotetext{
${ }^{1}$ Graduado em Administração. Mestre em Engenharia de Produção (UTFPR). Doutorando em Engenharia de Produção (UFSC). E-mail: thpalvarenga@hotmail.com

2 Graduada em Agronomia. Doutora em Genética Molecular (University of Reading - Inglaterra). Professora do Programa de Pós-Graduação em Engenharia de Produção (UTFPR - Ponta Grossa), Líder do Grupo de Pesquisa em Gestão da Inovação Agroindustrial (UTFPR - Ponta Grossa). E-mail: julianavitoria@utfpr.edu.br ${ }^{3}$ Doutor em Ingenieur-Ökonomie (Technische Universität Dresden - Alemanha). Professor do Programa de Pós-Graduação em Engenharia de Produção e Sistemas (UFSC). E-mail: carlos.taboada@ufsc.br
} 


\section{INTRODUÇÃO}

O hábito alimentar do brasileiro sofreu uma notável mudança a partir de meados da década de 1990. Esse fato ocorreu em virtude da queda do preço do leite e de seus derivados, sendo que a partir desse período a população das camadas mais baixas adquiriu poder de compra para esse tipo de produto (GOUVEIA, 2006; SCALCO, 1998).

Nesse contexto, de forma estratégica, indústrias de grande porte nacionais e multinacionais investiram na produção de lácteos, da mesma forma que as de pequeno porte, buscando retenção de parte da fatia desse mercado em desenvolvimento. Essa busca por tal mercado resultou em uma ampla concorrência entre as grandes indústrias de laticínios e os laticínios de pequeno porte (ALVARENGA et al., 2012).

A manutenção da competitividade dos laticínios brasileiros está ligada diretamente a sua gestão da qualidade. Tendo em vista que o mercado nacional está sendo ameaçado por produtos oriundos dos países do Mercado Comum do Sul (MERCOSUL) em função do seu baixo custo de produção, uma importante condicionante para que os laticínios nacionais se mantenham no mercado é através da melhoria da qualidade do produto. Outra importante condicionante é a de uma gestão da qualidade eficaz baseada na redução de custos e de desperdícios (SCALCO; TOLEDO, 2002).

A qualidade do leite consumido no país é uma constante preocupação dos técnicos e autoridades ligadas à área de saúde e laticínios. Um dos problemas encontrados na produção no leite é a realização de diversas fraudes que trazem prejuízos econômicos e riscos à saúde dos consumidores, além de problemas para as indústrias, como a diminuição do rendimento industrial (ROBIM et al., 2012), sendo necessária uma gestão da qualidade efetiva para combater esses problemas.

No caso específico do estado do Paraná, este vem se destacando nos últimos anos no cenário nacional tanto na produção leiteira como na produção industrial. Segundo dados do IBGE, o estado produz 3,3 bilhões de litros de leite/ano, ocupando a terceira colocação no ranking nacional de produção de leite, sendo que desse total são processados 2,1 bilhões de litros de leite/ano, ou seja, $67 \%$ da produção. (BAPTISTA; SUGAMOSTO; WAVRUK, 2011).

Do total de empresas de laticínios presentes no estado, $83 \%$ são micro e pequenas indústrias (IPARDES, 2010), isso reforça ainda mais a necessidade de estudos que investiguem a realidade da gestão da qualidade nestes estabelecimentos. Recentemente, estudos que focam em agroindústrias como o trabalho de Pasche e Ferreira (2010), e em consumidores como o trabalho de Souza et al. (2016), têm mostrado a importância do enfoque da qualidade, reforçando ainda mais a importância de pesquisas sobre este cerne.

Assim, o objetivo deste artigo é retratar a realidade da gestão da qualidade nos laticínios de micro e pequeno porte da região dos Campos Gerais - PR sob o ponto de vista das "Eras" da qualidade elaboradas por Garvin (2002). Estas "Eras" correspondem a etapas evolutivas da qualidade, sendo representadas pela "Era" da inspeção, do controle estatístico, da garantia da qualidade e do gerenciamento estratégico da qualidade. Portanto, a identificação de qual "Era" da qualidade os laticínios pesquisados estão inseridos torna-se o propósito deste estudo. 


\section{QUALIDADE}

Em relação ao termo qualidade, existem certas dificuldades em relação a sua definição por se tratar de um termo muito abrangente e pelo fato de seus conceitos tentarem dar um sentido único à qualidade. Seu conceito é utilizado diariamente pelas pessoas ao consumirem um produto ou um serviço. Assim, o modo como uma empresa conceitua e entende o termo qualidade espelha o modo como ela direciona suas atividades na produção de bens e serviços (MÉLO, 2007).

Garvin (2002), afirma que a definição sobre qualidade na literatura é vasta, sendo que esta pode ser definida através de cinco abordagens principais.

A primeira abordagem (transcendente) define qualidade como uma excelência inata, absoluta e universalmente reconhecível. A segunda (baseada no produto) conceitua qualidade como uma variável precisa e mensurável. Nesse caso, as diferenças de qualidade refletem nas diferenças de quantidades de insumos ou atributos de um determinado produto. A terceira abordagem (baseada no usuário) conceitua qualidade como a satisfação dos desejos e necessidades do consumidor. Essa abordagem é classificada pelo autor como uma abordagem subjetiva. A quarta abordagem (baseada na produção) conceitua qualidade como conformidade em relação às especificações. Assim, uma vez estabelecido um projeto ou uma especificação, qualquer desvio implica uma queda de qualidade. A quinta e última abordagem (baseada no valor) conceitua qualidade como um produto que oferece um desempenho ou conformidade a um custo aceitável (GARVIN, 2002).

O quadro 1 apresenta algumas definições sobre o termo qualidade além das previamente apresentadas:

Quadro 1 - Definições sobre a qualidade

\begin{tabular}{|c|c|}
\hline Autor & Definição \\
\hline Deming (1990) & $\begin{array}{l}\text { Consiste em produzir a quantidade planejada e atender às } \\
\text { especificações esperadas pelos clientes. }\end{array}$ \\
\hline Juran e Gryna (1991) & $\begin{array}{l}\text { Consiste nas características de um produto ou um serviço que } \\
\text { vão ao encontro das necessidades e, posteriormente, da } \\
\text { satisfação dos clientes. }\end{array}$ \\
\hline Montgomery (2009) & $\begin{array}{l}\text { Adequação ao uso, ou seja, a qualidade baseia-se no ponto de } \\
\text { vista de que produtos e serviços devem apresentar } \\
\text { especificações exigidas pelos consumidores. }\end{array}$ \\
\hline Slack et al. (2009) & $\begin{array}{l}\text { Qualidade é produzir produtos ou serviços sem defeitos e dentro } \\
\text { das especificações. }\end{array}$ \\
\hline
\end{tabular}

A qualidade de um produto pode ser analisada através de um conjunto de características e parâmetros, específicos de cada caso, que são intrínsecos ou que estão diretamente ligados ao produto. Assim, um produto pode ser descrito como um produto físico e como produto ampliado, ou seja, além do produto propriamente dito, são considerados sua embalagem, orientações para utilização, sua imagem, seus serviços pós-venda e outras características vinculadas ao produto (TOLEDO; BATALHA; AMARAL, 2000). Entretanto, para um entendimento mais aprofundado do tema qualidade são necessários conhecimentos à cerca da sua evolução, ou seja, as suas respectivas "Eras" (GARVIN, 2002). 


\section{ERAS DA QUALIDADE}

O conceito da palavra "qualidade" é dinâmico e esse evoluiu de forma significativa no século XX (BARBOSA, 2010). Devido à evolução desse conceito, nasceu a afirmação de que qualidade era de extrema importância para o posicionamento estratégico da empresa (MÉLO, 2007).

Garvin (2002) e Paladini (2008) defendem que a qualidade é conhecida há milênios e que o seu gerenciamento evoluiu no contexto histórico se dividindo em quatro etapas denominadas "Eras" da qualidade. Essas etapas representam o conceito de qualidade e de seu gerenciamento no decorrer da história, sendo elas representadas pelas "Eras" da Inspeção, do Controle Estatístico, da Garantia e da Gestão Estratégica da Qualidade (PASCHE; FERREIRA, 2010). Essas etapas estão inseridas no decorrer dos anos conforme a figura 1:

Figura 1 - Evolução da qualidade e suas "Eras"

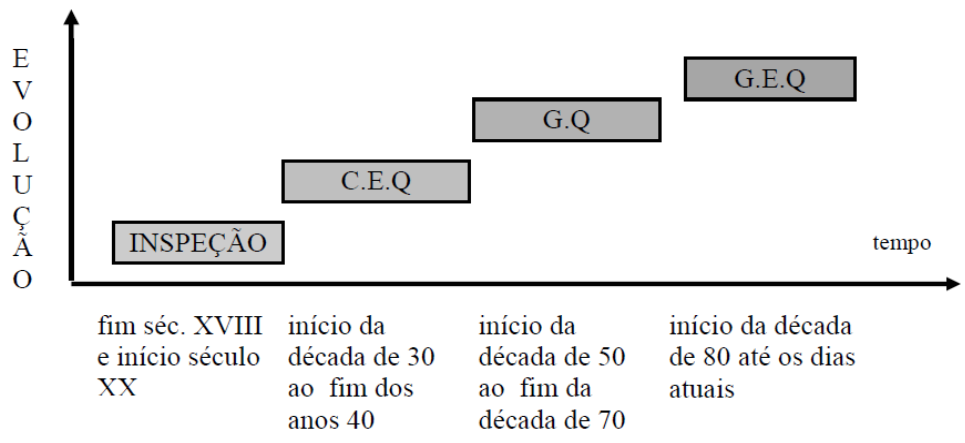

Fonte: Scalco(2004).

A primeira "Era" ou "Era da Inspeção" ocorreu nos séculos XVIII e XIX e a qualidade do produto era facilmente assegurada pela inspeção do próprio operário, decorrente da produção artesanal em pequenos lotes de produtos. Entretanto, tais inspeções passaram a não ser mais suficientes em decorrência do aumento da produção (GARVIN, 2002; SCALCO, 2004).

A segunda "Era" ou "Era do Controle Estatístico da Qualidade" corresponde ao período do controle da qualidade, através da utilização de ferramentas estatísticas e de amostragem (DAHMER, 2006). Nessa etapa, a preocupação já não era mais a inspeção do produto, sendo que na década de 1930 já havia uma tendência focada em controlar a qualidade. A Segunda Guerra Mundial exigiu que outras técnicas de controle fossem desenvolvidas com 0 intuito de suprir a impraticabilidade e ineficiência da inspeção "produto a produto" nas indústrias bélicas (BUENO, 2006). Assim, o departamento de guerra americano formou um grupo de estatísticos para a elaboração dessas técnicas, que foram muito eficazes, sendo inclusive disseminadas para outros ramos industriais (SCALCO, 2004).

Na terceira "Era" ou "Era da Garantia da Qualidade", a qualidade passou a ter atribuições mais amplas, porém o enfoque na prevenção de problemas ainda era o seu principal objetivo durante as décadas de 1950 a 1970 (SCALCO, 2004). Segundo Campos (2004, p. 113), "a garantia da qualidade é um processo sistemático de verificação para certificar-se de que a inspeção e as operações de controle da qualidade estão sendo conduzidas de forma correta". 
A "Era da Garantia da Qualidade" focou-se na integração de todos os colaboradores e de todos os departamentos da organização para que a qualidade fosse garantida através da execução eficaz de todas as atividades dentro da organização (BUENO, 2006). Nessa "Era" aparece a primeira abordagem sistêmica com o envolvimento de todas as áreas da organização e não somente a produção. Posteriormente, essa abordagem viria a influenciar as normas da International Organization for Standartization - ISO (LASCELLES; DAE, 1993 apud CARVALHO, 2008).

A partir do final da década de 1970 os Estados Unidos obtiveram uma queda no seu desempenho no mercado internacional. Tal queda foi agravada em razão da qualidade dos produtos japoneses ser nitidamente superior à dos produtos americanos. $\mathrm{O}$ advento da indústria japonesa evidenciou que a qualidade do produto focada na satisfação dos clientes poderia ser usada como um atributo de vantagem competitiva (MÉLO, 2007).

Na última "Era", ou seja, na "Era da Gestão Estratégica da Qualidade" há uma convicção de que a qualidade é definida pelo gosto dos consumidores, sendo eles os responsáveis pela aceitação da qualidade e não os departamentos de inspeção. Nessa "Era", o foco nas especificações tornou-se um atributo secundário, sendo que esse só pode ser priorizado após uma profunda identificação das necessidades dos consumidores (GARVIN, 2002).

\section{GESTÃO DA QUALIDADE NA PRODUÇÃO DE ALIMENTOS}

Quando se fala em qualidade nas indústrias de alimentos, o aspecto segurança do produto é sempre um fator determinante, pois qualquer problema de contaminação pode comprometer a saúde do consumidor (FIGUEIREDO; COSTA NETO, 2001). No entanto, a relação entre a segurança e a qualidade de um alimento nem sempre são inseparáveis no que tange a sua inocuidade e qualidade. Para um alimento ou um produto alimentício possuir um mínimo atributo de qualidade é necessário que o mesmo seja seguro para a saúde do homem. Entretanto, um alimento que satisfaça os atributos de segurança, nem sempre apresenta uma qualidade que satisfaça as exigências e necessidades do mercado (BORRÁS, 2005).

Em relação à importância dos padrões de qualidade de apresentação dos produtos alimentares, a gestão da qualidade abrange a aplicação de métodos que possam analisar a qualidade percebida pelo consumidor e identificar os requisitos de qualidade que ele deseja, uma vez que propriedades sensoriais e de forma de apresentação do produto são aspectos priorizados pelo consumidor (SANTOS; ANTONELLI, 2011).

A qualidade do produto alimentício é analisada através de duas perspectivas, sendo uma objetiva e outra subjetiva. A primeira trata-se de um conjunto de características intrínsecas ao produto, como as características físicas, nutricionais e higiênicas. A segunda está diretamente ligada ao gosto do consumidor em relação aos aspectos de qualidade sensoriais, como sabor, textura, forma, viscosidade e etc. (SANTOS; ANTONELLI, 2011; SCALCO; TOLEDO, 2002). A figura 2 apresenta essas perspectivas e suas características: 
Figura 2 - Perspectivas da qualidade do produto alimentício

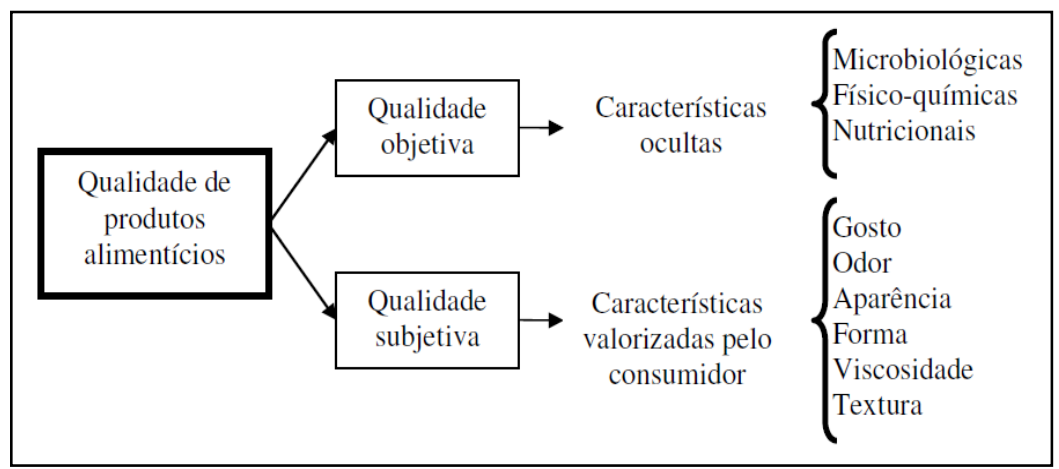

Fonte: Scalco (2004).

Os consumidores estão cada vez mais exigentes em relação à sua expectativa no momento de adquirir e/ou consumir um determinado produto. Empresas que não estão dando a devida atenção aos requisitos de qualidade poderão ficar a margem do mercado consumidor ou então serem extintas permanentemente (FIGUEIREDO; COSTA NETO, 2001).

Devido a essas exigências, é importante frisar que um problema de qualidade ocasionado por um produto impróprio para o consumo pode manchar a imagem de uma marca, comprometendo-a definitivamente. Assim, dificilmente um consumidor que viu sua saúde comprometida pela ingestão de um produto deteriorado ou contaminado arriscaria outra vez e certamente evitaria comprar tal produto de todas as maneiras (TOLEDO; BATALHA; AMARAL, 2000).

\subsection{FERRAMENTAS E METODOLOGIAS DA QUALIDADE NA PRODUÇÃO DE ALIMENTOS}

A crescente preocupação que o tema qualidade em alimentos tem despertado é notória e, concomitantemente, várias ferramentas de gestão da qualidade têm sido formuladas e utilizadas com o intuito de atender a quesitos em respeito ao consumidor, para oferecer um produto seguro e, ao mesmo tempo, assegurar as exigências de comercialização, principalmente as de exportação, nas quais os critérios são bem mais rigorosos. Isso também propicia a diminuição de custos, gerada pela redução de perdas e otimização da produção, dentre outros benefícios (FURTINI; ABREU, 2006).

Nesse contexto, existem diversas metodologias e ferramentas que seguem uma abordagem para garantia da qualidade, sendo que algumas foram elaboradas exclusivamente para 0 setor de alimentos e outras adaptadas para tal setor (SCALCO, 2004).

Em relação à gestão da qualidade na produção de alimentos é de suma importância à utilização de ferramentas como as Boas Práticas de Fabricação (BPF), Monitoramento Integrado de Pragas (MIP), Sistemas de Rastreabilidade, Análise de Perigos e Pontos Críticos de Controle (APPCC), além daquelas que são utilizadas em qualquer setor industrial como a ISO 9000, dentre outras (MONTEIRO, 2005). O quadro 2 apresenta as metodologias e ferramentas da qualidade mais utilizadas nas indústrias de alimentos: 


\section{Quadro 2 - Ferramentas/metodologias da qualidade utilizadas nas indústrias de alimentos}

\begin{tabular}{|c|c|}
\hline $\begin{array}{l}\text { Ferramentas da } \\
\text { qualidade }\end{array}$ & Descrição \\
\hline Folha de verificação (FV) & $\begin{array}{l}\text { A Folha de Verificação é, basicamente, uma planilha para o lançamento do } \\
\text { número de determinadas ocorrências de um evento. Sua aplicação } \\
\text { principal está relacionada com a observação de fenômenos. Nela, } \\
\text { observa-se o número de ocorrências de um problema e simultaneamente } \\
\text { anota-se na folha, de forma simplificada, a sua frequência (LINS, 1993). }\end{array}$ \\
\hline $\begin{array}{l}\text { Controle Estatístico de } \\
\text { Processo (CEP) }\end{array}$ & $\begin{array}{l}\text { O Controle Estatístico de Processo (CEP) é um conjunto de ferramentas } \\
\text { estatísticas que auxiliam na resolução de problemas no ambiente de } \\
\text { processos e na tomada de decisão por parte dos gestores de qualidade e } \\
\text { de seus colaboradores. O CEP busca a exatidão na fabricação, utilizando- } \\
\text { se de dados para analisar o processo. No processo o CEP previne perdas } \\
\text { (desperdício) de produtos, através de limites estritamente especificados } \\
\text { (DINIZ, 2001; MONTGOMERY 2009). }\end{array}$ \\
\hline $\begin{array}{l}\text { Boas Práticas de } \\
\text { Fabricação (BPF) }\end{array}$ & $\begin{array}{l}\text { As Boas Práticas de Fabricação são um conjunto de normas e } \\
\text { procedimentos para o alcance de um padrão de qualidade e identidade de } \\
\text { um determinado produto ou serviço na área de alimentos, abrangendo } \\
\text { bebidas, utensílios, recipientes e materiais em contato com alimentos } \\
\text { (BRASIL, 1993). } \\
\text { As BPF são ferramentas específicas do setor de alimentos e focam-se em } \\
\text { padrões higiênicos de manipulação e fabricação de produtos, com o intuito } \\
\text { de que não haja contaminação em nenhuma das etapas do processo } \\
\text { (SCALCO, 2004). }\end{array}$ \\
\hline $\begin{array}{l}\text { Monitoramento integrado } \\
\text { de pragas (MIP) }\end{array}$ & $\begin{array}{l}\text { A existência de insetos, roedores e demais animais em uma indústria } \\
\text { alimentícia é considerado violações contra a sanidade. A necessidade de } \\
\text { se controlar a invasão dessas pragas nos estabelecimentos industriais e } \\
\text { de estocagem é de extrema importância (SCALCO, 2004). } \\
\text { O Monitoramento Integrado de Pragas é uma ferramenta não somente } \\
\text { destinada ao controle de pragas em ambientes industriais, mas também } \\
\text { em instalações leiteiras que são frequentemente alvo de doenças } \\
\text { ocasionadas principalmente por roedores (VIEIRA apud SCALCO, 2004). }\end{array}$ \\
\hline $\begin{array}{l}\text { Procedimento Padrão de } \\
\text { Higiene Operacional } \\
\text { (PPHO) }\end{array}$ & $\begin{array}{l}\text { O Procedimento Padrão de Higiene Operacional (PPHO) advém do inglês } \\
\text { Standard Sanitizing Operating Procedures (SSOP) e é representado por } \\
\text { requisitos de Boas Práticas de Fabricação considerados críticos na cadeia } \\
\text { produtiva de alimentos (FURTINI; ABREU, 2006). } \\
\text { Os PPHO's são procedimentos que buscam estabelecer a forma "rotineira- } \\
\text { padrão" pela qual um estabelecimento industrial irá realizar suas } \\
\text { atividades. Seu objetivo é evitar a contaminação direta ou cruzada e a } \\
\text { adulteração do produto, preservando sua qualidade e integridade por meio } \\
\text { da higiene antes, durante e depois das operações industriais (BRASIL, } \\
2003 \text { ). }\end{array}$ \\
\hline $\begin{array}{l}\text { Análise de Perigos e } \\
\text { Pontos Críticos de } \\
\text { Controle (APPCC) }\end{array}$ & $\begin{array}{l}\text { A Análise de Perigos e Pontos Críticos de Controle da sigla em inglês } \\
\text { HACCP (Hazard Analisys and Critical Control Points) teve seu início na } \\
\text { década de } 1950 \text { em indústrias químicas na Grã-Bretanha e, nos anos de } \\
1960 \text { e } 1970 \text {, foi amplamente usada nas plantas de energia nuclear e } \\
\text { adaptada para o setor de alimentos pela Pillsbury Company, por } \\
\text { solicitação da Agência Espacial Americana (NASA), para que não } \\
\text { ocorresse nenhum problema com os astronautas relativo a enfermidades } \\
\text { transmitidas por alimentos (ETA) e equipamentos em pleno vôo } \\
\text { (HARRIGAN, 1993). O APPCC é baseado numa série de etapas inerentes } \\
\text { ao processamento industrial dos alimentos, abrangendo todas as } \\
\text { atividades que ocorrem desde a obtenção da matéria-prima até ao } \\
\text { consumo, fundamentando-se na identificação dos perigos potenciais à } \\
\text { saúde do consumidor, bem como nas medidas de controle das condições } \\
\text { que geram os perigos (FURTINI; ABREU, 2006). }\end{array}$ \\
\hline
\end{tabular}

(Continua) 
(Conclusão)

\begin{tabular}{|l|l|}
\hline $\begin{array}{l}\text { Ferramentas da } \\
\text { qualidade }\end{array}$ & Descrição \\
\hline \multirow{5}{*}{ ISO 9000} & $\begin{array}{l}\text { O sistema ISO 9000 é uma norma que promove a adoção de uma } \\
\text { abordagem de processo para o desenvolvimento, implementação e } \\
\text { melhoria da eficácia de um sistema de gestão da qualidade com o objetivo } \\
\text { de aumentar a satisfação dos clientes, através do atendimento a requisitos } \\
\text { que eles necessitam (MEIRA; CERON, 2004). } \\
\text { Essas normas estabelecem requisitos que estão divididos em cinco } \\
\text { seções, sendo elas: o sistema de gestão da qualidade que trata dos } \\
\text { objetivos; o registro e documentação para a qualidade; responsabilidade } \\
\text { da administração que trata dos compromissos dos gestores e a } \\
\text { disponibilidade dos recursos necessários; gestão de recursos que trata } \\
\text { das pessoas, ambiente e materiais necessários; realização do produto que } \\
\text { trata dos modos da condução da operação, medição, prevenção e ações } \\
\text { de melhoria (SANTOS; MEDEIROS, 2008). }\end{array}$ \\
\hline $\begin{array}{l}\text { Segundo Silva e Gonçalves (2006), o Desdobramento da Função } \\
\text { Qualidade é uma ferramenta sistemática de planejamento e } \\
\text { desenvolvimento da qualidade. Tal ferramenta se caracteriza por ser } \\
\text { método específico de ouvir os clientes o que os clientes desejam e, em } \\
\text { seguida, utilizar um sistema para determinar a melhor forma de atender a } \\
\text { esses desejos com os recursos disponíveis. Essa ferramenta é executada } \\
\text { conforme Benner et al. (2003), através de matrizes que vinculam os } \\
\text { requisitos implícitos dos consumidores e sua tradução em parâmetros de } \\
\text { projeto. }\end{array}$ \\
\hline $\begin{array}{l}\text { O conceito de rastreabilidade está diretamente associado à identificação } \\
\text { de um determinado produto nas mais diversas etapas do processo } \\
\text { produtivo, podendo ser em termos locacionais, sobre atributos ou sobre } \\
\text { suas características (MACHADO, 2005). } \\
\text { No contexto da gestão da qualidade, a rastreabilidade é uma ferramenta } \\
\text { capaz de coletar e armazenar dados, com o objetivo de conseguir } \\
\text { conhecimento da real situação de um produto em qualquer local da sua } \\
\text { cadeia produtiva para, se necessário, executar correções, melhorias e } \\
\text { incrementos (SCALCO, 2004). }\end{array}$ \\
\hline Fonte: Elaboradidade (RT)
\end{tabular}

\section{METODOLOGIA}

No que tange a natureza da presente pesquisa, essa pode ser classificada como aplicada, pois visa gerar conhecimentos para a aplicação prática, voltada para a solução de problemas e interesses locais, no caso, a região dos Campos Gerais no estado do Paraná (GIL, 2002).

Em relação à abordagem, essa pesquisa pode se caracterizar como qualitativa, pois segundo Godoy (1995), parte de questões de interesses amplos que se definem durante o desenvolvimento do estudo envolvendo a obtenção de dados descritivos sobre pessoas, empresas e processos através do contato direto do pesquisador com a situação estudada.

Quanto ao tipo da pesquisa, essa pode ser considera um levantamento, pois visa coletar dados de um grupo considerável de pessoas/empresas sobre um determinado problema (GIL, 2002).

Quanto aos objetivos da pesquisa, essa assume um caráter descritivo, pois visa descrever as características de uma determinada população (Laticínios de micro e pequeno porte dos Campos Gerais - PR), envolvendo o uso de técnicas padronizadas de coleta de dados como o questionário (GIL, 2002).

Os questionários na sua grande maioria são utilizados para obter uma grande quantidade de dados diretamente da fonte da informação não sendo necessário lançar mão de dados secundários que em sua maioria são escassos e nem sempre representam a realidade atual (RUIZ, 1996). 
Com o intuito de atingir o objetivo dessa pesquisa de identificar o cenário da gestão da qualidade, restringiram-se como critérios de seleção: as indústrias de laticínios de micro e pequeno porte, localizadas na região dos Campos Gerais no Estado do Paraná, que possuem registro no Serviço de Inspeção Paranaense de Produtos de Origem Animal (SIP-POA) e no Serviço de Inspeção Federal (S.I.F.), conforme o mapa da figura 3:

Figura 3 - Mapa do estado Paraná com a região dos Campos Gerais em destaque

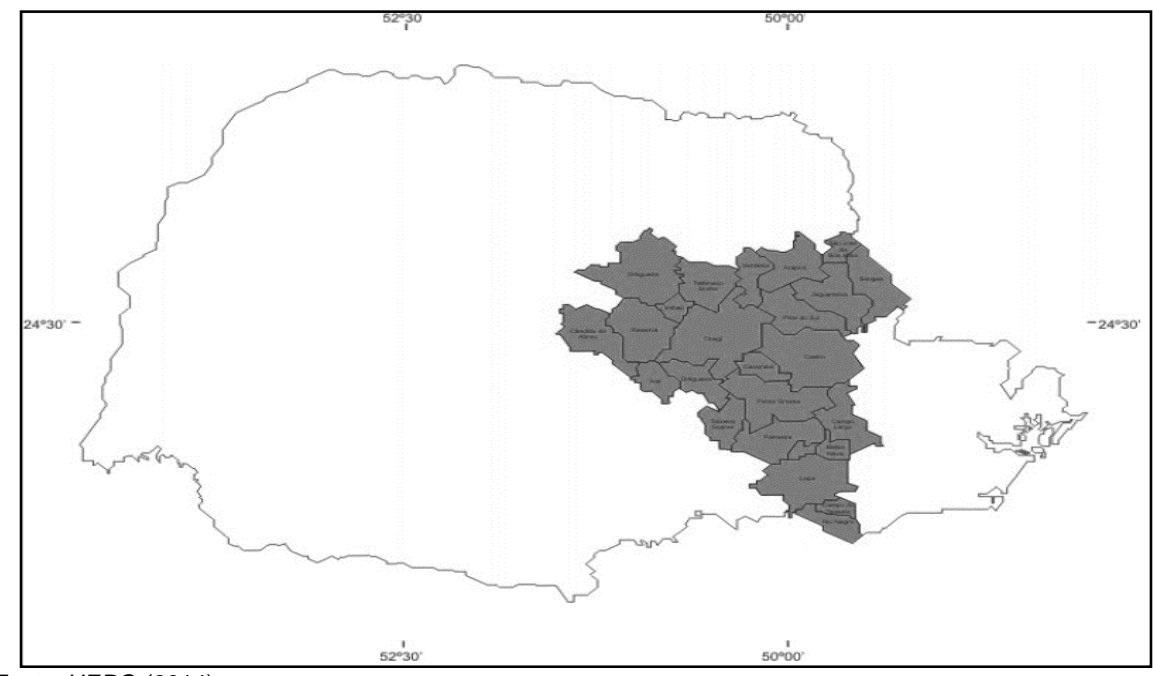

Fonte: UEPG (2014).

Para a identificação dos municípios que integraram essa região foram considerados os municípios descritos no Dicionário Histórico e Geográfico dos Campos Gerais da Universidade Estadual de Ponta Grossa (2013). Sendo assim, os municípios integrantes desta região são: Arapoti, Campo do Tenente, Cândido Abreu, Castro, Ipiranga, Jaguariaíva, Ortigueira, Piraí do Sul, Porto Amazonas, Reserva, Telêmaco Borba, Tibagi, Balsa Nova, Campo Largo, Carambeí, Imbaú, Ivaí, Lapa, Palmeira, Ponta Grossa, Rio Negro, São José da Boa Vista, Teixeira Soares e Ventania.

O questionário foi aplicado nos meses de setembro e outubro de 2013, para um universo de 13 laticínios, sendo que deste universo, somente 3 laticínios não responderam, totalizando 10 laticínios respondentes, ou $77 \%$ de toda a população.

Os dados foram analisados conforme Bueno (2006), onde a utilização das ferramentas/metodologias da qualidade demonstra em qual "Era" uma organização se encontra. O Quadro 3 apresenta as ferramentas e suas respectivas "Eras" da qualidade:

Quadro 3 - Ferramentas/metodologias da qualidade em relação as "Eras"

\begin{tabular}{|l|l|}
\hline Eras da qualidade & Ferramentas/metodologias \\
\hline Inspeção & FV \\
\hline Controle da qualidade & CEP \\
\hline Garantia da qualidade & BPF, PPHO, MIP, APPCC e ISO 9000 \\
\hline Gestão estratégica da qualidade & QFD e RT \\
\hline \\
Fonte: Bueno (2006).
\end{tabular}


As características de cada "Era" e os objetivos de cada ferramenta/metodologia possibilitam o posicionamento das empresas nas respectivas "Eras" da qualidade (BUENO, 2006). Com as ferramentas/metodologias da qualidade identificadas foi possível identificar o nível de utilização e implantação de cada ferramenta/metodologia, conforme a pesquisa de Scalco e Toledo (2002).

\section{RESULTADOS E DISCUSSÕES}

Neste item serão apresentados os resultados obtidos no estudo junto aos 10 laticínios pesquisados da região dos Campos Gerais do Paraná.

\subsection{QUANTO AO NÚMERO DE FUNCIONÁRIOS}

A importância das micro e pequenas empresas na geração de empregos para o país é um fato público (FONSECA, 2012). Nesse contexto, é importante o conhecimento do número de funcionários das indústrias pesquisadas para a verificação de que as mesmas são de micro e pequeno porte e para se mensurar a quantidade de empregos que tais laticínios representam dentro de um contexto social.

O porte de uma empresa pode ser classificado através do seu número de funcionários. A tabela 1 apresenta essa classificação:

Tabela 1 - Classificação do porte das empresas

\begin{tabular}{lrr}
\hline Porte da empresa & $\begin{array}{c}\text { Número de funcionários na } \\
\text { Indústria }\end{array}$ & $\begin{array}{c}\text { Número de funcionários no } \\
\text { comércio }\end{array}$ \\
\hline Microempresa & até 19 & até 9 \\
Pequena empresa & de 20 a 99 & de 10 a 49 \\
Média empresa & de 100 a 499 & de 50 a 99 \\
Grande empresa & acima de 500 & acima de 100
\end{tabular}

Fonte: SEBRAE (2004)

A tabela 2 apresenta o número de funcionários dos laticínios pesquisados, satisfazendo a classificação apresentada pelo SEBRAE (2004) como de micro e pequeno porte:

Tabela 2 - Número de funcionários dos laticínios pesquisados

\begin{tabular}{cr}
\hline $\begin{array}{l}\text { Indústria de } \\
\text { laticínio }\end{array}$ & $\begin{array}{c}\text { Número de } \\
\text { funcionários }\end{array}$ \\
\cline { 2 - 3 } & Laticínio A \\
Laticínio B & 7 \\
Laticínio C & 10 \\
Laticínio D & 12 \\
Laticínio E & 8 \\
Laticínio F & 24 \\
Laticínio G & 35 \\
Laticínio H & 26 \\
Laticínio I & 35 \\
Fonte: Dados & 30 \\
\cline { 2 - 2 } da pesquínio J & 32 \\
\hline
\end{tabular}


Conforme os dados da tabela 2, é notório a importância das micro e pequenas empresas na geração de empregos. Nota-se que os laticínios pesquisados são responsáveis pela geração de mais de duzentos postos de trabalho. Essa representatividade é uma característica das micro e pequenas empresas. Elas possuem uma expressiva participação no total da geração de empregos no país, superior a 50\% do total de vagas (FONSECA, 2012; REZENDE; ANDRADE; REZENDE, 2004).

\subsection{QUANTO AO TEMPO DE ATUAÇÃO NO MERCADO}

Pesquisas realizadas pelo Sistema Brasileiro de Apoio às Micro e Pequenas Empresas (SEBRAE) comprovam que sete em cada dez empresas brasileiras encerram suas atividades antes dos cinco anos de vida. Sendo assim, o tempo de existência de uma empresa representa a sua capacidade técnica ou sua competitividade no mercado. Nesse contexto, o tempo de atuação no mercado dos laticínios pesquisados será apresentado na figura 4:

Figura 4 - Tempo de atuação dos laticínios no mercado

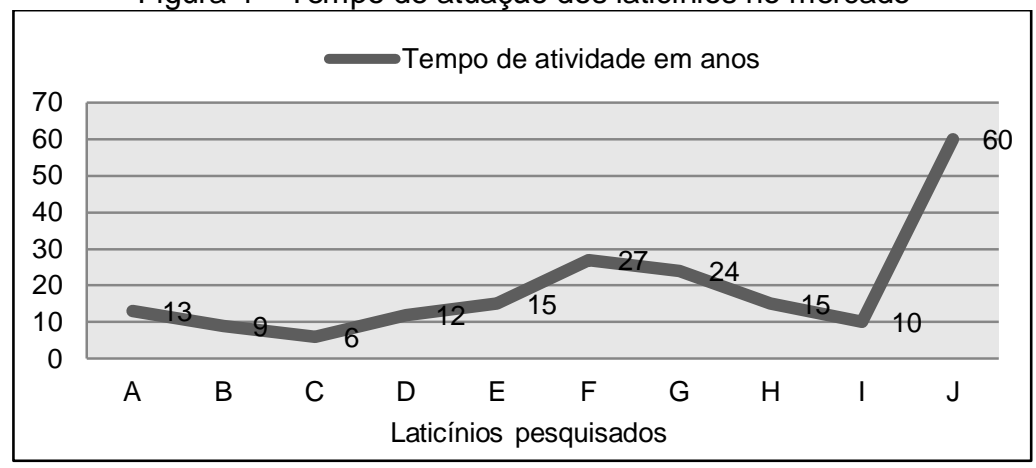

Fonte: Dados da pesquisa

Referente ao tempo de atuação no mercado por parte dos laticínios, o que se nota na Figura 4, é que esses já estão há anos no mercado e que já passaram pelos cinco primeiros anos considerados críticos pelo SEBRAE (2007) quanto à mortalidade das empresas. A figura 4 também demonstra laticínios maduros com mais de 20 anos de atuação e um laticínio com 60 anos de presença no mercado como o caso do laticínio J. Nota-se que os laticínios pesquisados já estão ambientados ao contexto mercadológico devido aos seus anos no mercado, sendo necessárias maiores atenções quanto as suas práticas de gestão.

\subsection{VOLUME DE PROCESSAMENTO DE LEITE}

O volume de processamento de litros de leite/dia representa a capacidade ou a quantidade demandada de leite e derivados processados pelo laticínio. Nesse contexto, dentro de um mesmo agrupamento de laticínios classificados como de micro e pequeno porte, pode-se ter uma diferença em relação ao volume de processamento desses laticínios.

No que tange ao número de funcionários, esses são maiores em laticínios que processam um volume maior de leite. A figura 5 apresenta um gráfico considerando esses dois quesitos: 
Figura 5 - Volume de leite processado e o número de funcionários

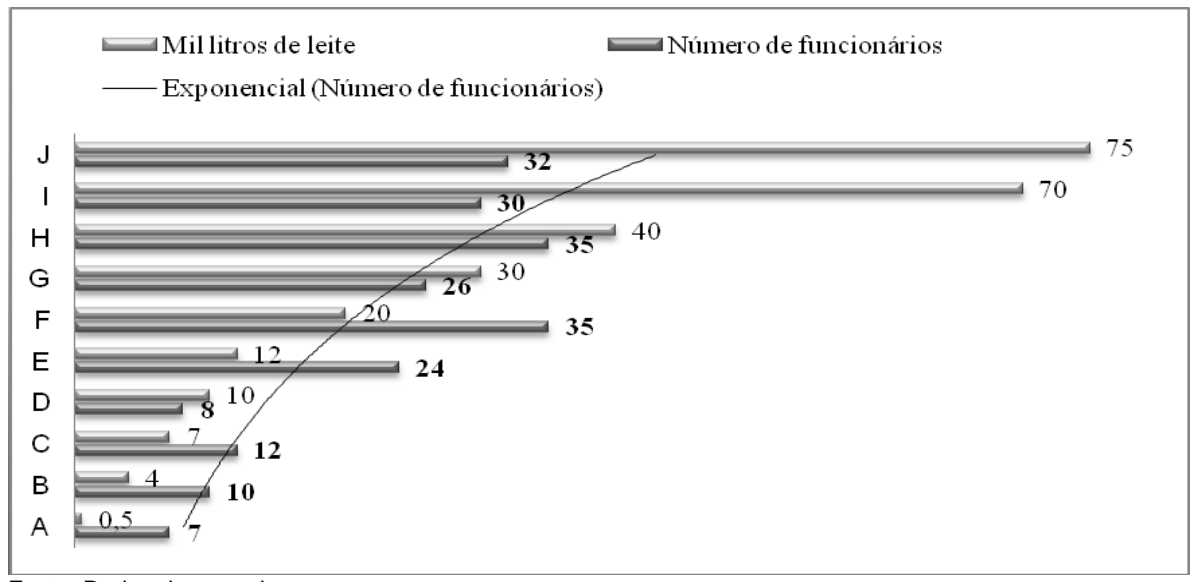

Fonte: Dados da pesquisa.

Na figura 5, é possível visualizar que os laticínios que processam um maior volume de leite, consequentemente, possuem um maior número de funcionários na sua produção. Contudo, nota-se que esse aumento não se apresenta de forma proporcional, o que é facilmente notado quando comparamos o número de funcionários do laticínio $A$ em relação ao laticínio $B$, em que o primeiro possui 7 funcionários e o segundo 10 funcionários. Nota-se que há uma pequena diferença de apenas 3 funcionários entre os laticínios, mesmo o laticínio B tendo um volume de processamento oito vezes maior.

Esse fato pode ser explicado devido ao desenvolvimento da agroindústria paranaense nos últimos anos, incluindo o setor de laticínios, através do incremento de novas tecnologias que propiciam o aumento da produtividade (GONÇALVES; PARRÉ 2010). Esse incremento de tecnologias é visualizado na produtividade do laticínio $\mathrm{J}$ na figura 5 , o qual processa 75.000 mil litros de leite/dia com 32 funcionários.

\subsection{QUANTO AOS PRODUTOS PROCESSADOS}

Através do processamento do leite obtêm-se um mix de vários produtos, desde produtos mais simples até produtos mais sofisticados. Belik (1994) afirma que a indústria agroalimentar brasileira, incluindo os laticínios, consegue maiores ganhos em termos de lucratividade ao colocar no mercado um mix de produtos maior. $\mathrm{O}$ Quadro 4 apresenta os produtos processados pelos laticínios pesquisados: 
Quadro 4 - Produtos processados pelos laticínios pesquisados

\begin{tabular}{|l|l|}
\hline LATICÍNIO & PRODUTOS PROCESSADOS \\
\hline A & Doce de leite \\
\hline B & Queijos \\
\hline C & Leite pasteurizado \\
\hline D & Leite pasteurizado \\
\hline E & $\begin{array}{l}\text { Queijos, leites fermentados, iogurte, creme de leite, doce de leite, manteiga e } \\
\text { requeijão }\end{array}$ \\
\hline F & Queijos e leite pasteurizado \\
\hline G & Queijos \\
\hline H & Leite pasteurizado, iogurte, doce de leite, queijos, requeijão e creme de leite \\
\hline I & Leite pasteurizado, bebida láctea e creme de leite \\
\hline J & Leite pasteurizado, leite longa vida e queijos \\
\hline
\end{tabular}

Fonte: Dados da pesquisa

Segundo Vilela e Macedo (2000), a permanência das agroindústrias no mercado depende da diferenciação da qualidade do produto e do aumento do mix de produtos ofertados. No Quadro 4, nota-se que cinco dos dez laticínios pesquisados processam mais que um produto (caso dos laticínios $E, F, H, I$ e J). Os demais laticínios ( $A, B, C, D$ e $G$ ) processam um único produto.

\subsection{QUANTO À EXISTÊNCIA DE UM RESPONSÁVEL PELA COORDENAÇÃO DA QUALIDADE}

Dos 10 laticínios pesquisados, todos destacaram a presença de um funcionário responsável pela coordenação da qualidade nas atividades produtivas. $\mathrm{O}$ Quadro 5 apresenta o perfil desses profissionais:

Quadro 5 - Perfil dos coordenadores de qualidade

\begin{tabular}{|l|l|l|}
\hline LATICÍNIO & FUNÇÃo & FORMAÇÃo \\
\hline A & Coordenador de qualidade & $2^{\circ}$ Grau Técnico (alimentos) \\
\hline B & Coordenador de qualidade & $2^{0}$ Grau Técnico (alimentos) \\
\hline C & Coordenador de qualidade & Química \\
\hline D & Responsável técnico & Medicina Veterinária \\
\hline E & Coordenador de qualidade & Tecnologia em Alimentos \\
\hline F & Coordenador de qualidade & Bioquímica \\
\hline G & Responsável técnico & Medicina Veterinária \\
\hline H & Coordenador de qualidade & Engenharia de Alimentos \\
\hline I & Coordenador de processos & Tecnologia em Alimentos \\
\hline J & Coordenador de qualidade & Engenharia de Alimentos \\
\hline
\end{tabular}

Fonte: Dados da pesquisa

Segundo Campos (2004) e Queiroz (1996), a presença de um funcionário responsável pela coordenação da qualidade na empresa é de suma importância para a organização, pois esse possui um perfil específico, o que o torna um líder entre os demais funcionários, facilitando uma cultura de motivação para a qualidade.

Nota-se que dos dez responsáveis pela qualidade dos laticínios pesquisados, oito possuem curso superior e dois possuem curso de segundo grau técnico, o que demonstra nível de instrução elevado mesmo os laticínios sendo caracterizados como empresas de micro e pequeno porte. 


\subsection{ANÁLISE E DISCUSSÃO DOS DADOS}

A utilização das ferramentas/metodologias da qualidade demonstra em qual "Era" uma organização se encontra. As características de cada "Era" e os objetivos de cada ferramenta/metodologia possibilita o posicionamento das organizações nas respectivas "Eras" da qualidade (BUENO, 2006).

Com as ferramentas/metodologias da qualidade identificadas é possível identificar o nível de utilização e implantação de cada ferramenta/metodologia, conforme Scalco e Toledo (2002). A tabela 3 apresenta o nível de intensidade da implantação das ferramentas/metodologias pelos laticínios pesquisados:

Tabela 3 - Níveis de implantação das ferramentas/metodologias da qualidade

\begin{tabular}{|c|c|c|c|c|c|}
\hline Ferramentas & $\begin{array}{c}\text { Não } \\
\text { implantada }\end{array}$ & $\begin{array}{c}\text { Não } \\
\text { implantada, } \\
\text { mas } \\
\text { achamos } \\
\text { necessário }\end{array}$ & $\begin{array}{c}\text { Em fase } \\
\text { inicial de } \\
\text { implantação }\end{array}$ & $\begin{array}{c}\text { Em fase final } \\
\text { de } \\
\text { implantação }\end{array}$ & $\begin{array}{l}\text { Totalmente } \\
\text { implantada }\end{array}$ \\
\hline FV & - & - & - & - & $100 \%$ \\
\hline CEP & $20 \%$ & $40 \%$ & $20 \%$ & $20 \%$ & \\
\hline BPF & - & - & - & - & $100 \%$ \\
\hline $\mathrm{PPHO}$ & - & - & - & - & $100 \%$ \\
\hline MIP & - & - & - & - & $100 \%$ \\
\hline APPCC & - & - & $60 \%$ & $30 \%$ & $10 \%$ \\
\hline ISO 9000 & $80 \%$ & $10 \%$ & $10 \%$ & - & - \\
\hline QFD & $20 \%$ & $70 \%$ & $10 \%$ & - & - \\
\hline $\mathrm{RT}$ & $30 \%$ & $40 \%$ & $20 \%$ & $10 \%$ & - \\
\hline
\end{tabular}

Fonte: Dados da pesquisa

Em relação à ferramenta Folha de Verificação (FV), todos os laticínios pesquisados já implantaram essa ferramenta em suas atividades. A utilização dessa ferramenta pelos laticínios facilita a coleta de dados estabelecidos pelas instruções normativas específicas do setor de laticínios, a exemplo da Instrução Normativa $\mathrm{N}^{\circ} 62 / 2011$ que estipula padrões de qualidade do leite a serem verificados.

O Controle Estatístico de Processo (CEP) não está implantado em $20 \%$ dos laticínios pesquisados; em $40 \%$ deles não está implantado, mas é considerado necessário; em 20\% deles está em fase inicial de implantação; em $20 \%$ deles está em fase final de implantação. Essa ausência da utilização de técnicas estatísticas também foi identificada na pesquisa de Scalco e Toledo (2002).

A ferramenta Boas Práticas de Fabricação (BPF), Monitoramento Integrado de Pragas (MIP) e Procedimento Padrão de Higiene Operacional (PPHO) estão implantadas em $100 \%$ dos laticínios pesquisados. Esse comportamento por parte dos laticínios pesquisados demonstra o oposto da pesquisa realizada por Scalco e Toledo (2002) em laticínios, onde foi identificada a ausência de implantação de ferramentas específicas do setor, como a BPF e o MIP.

Contudo, há de se considerar que a pesquisa realizada por Scalco e Toledo foi publicada no ano de 2002, ou seja, há mais de uma década. Durante esses anos, foram elaboradas novas legislações, mais rigorosas em relação à qualidade do leite, a exemplo da Instrução Normativa no 51/2002 do Ministério da Agricultura, Pecuária e Abastecimento e da Instrução Normativa no 62/2011 do mesmo órgão.

Mais recentemente, a pesquisa realizada por Santos e Antonelli (2011), demonstrou que em indústrias de alimentos no estado de São Paulo, 95\% das que foram pesquisadas já possuíam a ferramenta Boas Práticas de Fabricação (BPF) totalmente implantada em seus processos produtivos e que o uso de técnicas 
estatísticas por essas indústrias depende da implantação efetiva da BPF e do APPCC.

O APPCC está em fase inicial de implantação em $60 \%$ dos laticínios pesquisados; em $30 \%$ deles está em fase final de implantação; em $10 \%$, ele está totalmente implantado. Uma pesquisa realizada por Oliveira et al. (2013) demonstrou que a principal dificuldade encontrada no atraso da implantação do APPCC é a falta de velocidade na realização de ações, principalmente quando estavam relacionadas com a necessidade de investimentos.

Numa outra pesquisa realizada por Spexoto, Oliveira e Olival (2005), identificou-se que as principais dificuldades encontradas na implantação do APPCC foram a motivação e envolvimento dos funcionários para a nova rotina de procedimentos e as dificuldades de tomada de decisão rápida, muitas vezes necessária para o controle de perigos e pontos críticos.

Contudo, o sistema APPCC tem sido largamente recomendado e requerido por órgãos de fiscalização por possuir a prevenção, a racionalidade e a especificidade para o controle dos riscos que um produto alimentício possa oferecer (FURTINI; ABREU, 2006).

Em relação a ISO $9000,80 \%$ dos laticínios pesquisados não possuem esta metodologia implantada. Em $10 \%$ dos laticínios, ela não está implantada, mas é considerada necessária e, em 10\%, ela está em fase inicial de implantação.

Essa ausência ocorre em virtude das pequenas empresas enfrentarem grandes dificuldades no que diz respeito aos investimentos necessários para a implementação e certificação da ISO 9000, em função do custo, disponibilidade de tempo e ausência de pessoal qualificado para conduzir a implementação (ESTÁCIO, 2003). Segundo Mendonça (2008), todas estas deficiências impedem as pequenas empresas de implementar e manter a ISO 9000. No Brasil, estas dificuldades também são presentes em empresas de grande porte (PINTO; CARVALHO; HO, 2006).

Uma pesquisa realizada por Godoy et al. (2009), com empresas com menos de 99 funcionários no Rio Grande do Sul, constatou que a implantação da ISO 9000, apesar de dispendiosa em relação aos custos para sua implantação, trouxe benefícios posteriores em relação ao investimento empregado, como o aumento das vendas e a redução de custos referentes a perdas e desperdícios que resultam em custos elevados de produção.

No que tange a ferramenta QFD, foi identificado que essa não está implantada em $20 \%$ dos laticínios, porém em $70 \%$ dos laticínios, embora não esteja implantada, é considerada necessária e, em 10\%, ela está em fase inicial de implantação. Segundo Carnevalli, Sassi e Miguel (2002), a ferramenta QFD é pouco utilizada no Brasil, sendo que a ausência de conhecimento e treinamento dos funcionários são as principais causas para a não utilização dessa ferramenta.

No entanto, a QFD é de grande valia para a obtenção de informações dos consumidores para a elaboração e aprimoramento de produtos alimentícios. Em diversas pesquisas (MARCOS; JORGE, 2002; MIGUEL et al., 2007; PINTO; PAIVA, 2010) em que houve a sua aplicação, essa ferramenta demonstrou grande eficiência.

Por último, no que se refere à Rastreabilidade, essa não está implantada em $30 \%$ dos laticínios; em $40 \%$ ela não está implantada, mas é considerada necessária; em $20 \%$ ela está em fase inicial de implantação; em $10 \%$, ela está em fase final de implantação.

A ausência da rastreabilidade nos laticínios pesquisados vai contra as necessidades dos atuais consumidores, pois segundo Vinholis e Azevedo (2002), a 
crescente preocupação dos consumidores em relação à segurança do produto vem impulsionando a adoção de sistemas de rastreabilidade em indústrias de alimentos.

Porém, o que muitas empresas não conseguem enxergar é que a rastreabilidade propicia a diferenciação de produtos, principalmente no Brasil, devido às diversas ocorrências de adulteração do leite (CONCHON; LOPES, 2012).

$\mathrm{Na}$ Europa, indústrias de laticínios desenvolveram e aplicaram sistemas de rastreabilidade para manter informações referentes ao leite fornecido por cada produtor, nos tanques de armazenamento de leite e nas etapas de processamento de produtos lácteos (DESANTIS; ZANINELLI; TANGORRA, 2006).

No Brasil, com os casos de adulteração de leite no Rio Grande do Sul, alguns laticínios iniciaram um processo de desenvolvimento de um sistema parecido com a rastreabilidade da carne bovina. No ano de 2010, a Aurora Alimentos criou o programa Produto Aurora Rastreado (PAR), juntamente com a fabricante de embalagens Tetra Pak. Nesse sistema, é possível consultar a origem das matériasprimas de todos os produtos da empresa. No caso específico do leite, se o consumidor desconfiar de alguma contaminação ou adulteração, ele pode rever todo o trajeto da fazenda ao ponto de venda através do PAR (OTOBONI; FERNANDES, 2013).

Através dessas análises o presente estudo conseguiu caracterizar que os laticínios de micro e pequeno porte dos Campos Gerais possuem diversas deficiências, sendo essas caracterizadas pelo déficit de ações estratégicas, como a ausência da participação dos consumidores no desenvolvimento de novos produtos e no desenvolvimento de sistemas de rastreabilidade.

Assim, os laticínios de micro e pequeno porte da região dos Campos Gerais do estado do Paraná estão posicionados na terceira etapa das "Eras da Qualidade", ou seja, na "Era" da garantia da qualidade.

\section{CONSIDERAÇÕES FINAIS}

Foi possível identificar através dos resultados em qual etapa das "Eras" da qualidade os laticínios de micro e pequeno porte da região dos Campos Gerais no Paraná estão posicionados. Mediante essa identificação, este trabalho pode auxiliar os laticínios dessa região a corrigir e adequar suas formas de gestão com as necessidades de qualidade exigidas pelo atual mercado.

A qualidade é um atributo essencial para qualquer organização, sendo ela em muitos casos ditada pelas próprias empresas, não levando em conta as necessidades dos clientes. No caso dos laticínios, esta realidade também é comum, na qual os produtos são oferecidos aos consumidores sem a prévia audição do seu mercado alvo.

Devido à exigência dos órgãos normativos e de fiscalização, a gestão da qualidade nos laticínios de micro e pequeno porte da região dos Campos Gerais é quase sempre limitada a fatores de segurança e de higiene. Isso ocorre em virtude de a legislação exigir a implantação de ferramentas da qualidade voltadas para a produção de alimentos livres de contaminações, o que faz com que os laticínios pesquisados possuam um conhecimento e um nível de implantação avançado sobre tais ferramentas. Por outro lado, há pouca implantação e utilização de ferramentas voltadas para a identificação das preferências dos consumidores em virtude de ser uma iniciativa dos próprios laticínios e não uma exigência legal.

No entanto, foram detectados profissionais responsáveis pela qualidade com níveis avançados de conhecimento técnico, o que facilita a implantação de ferramentas voltadas para a aquisição de informações explicitadas pelos 
consumidores, obtendo assim possibilidades de desenvolvimento de produtos com características exigidas pelo mercado.

O fato dos laticínios pesquisados estarem posicionados na "Era da Garantia da Qualidade" demonstra a necessidade desses estabelecimentos em buscar apoio em órgãos como o SEBRAE e de estreitar as relações com as universidades. Esse apoio proporcionado por esses órgãos facilita a obtenção de conhecimentos de gestão e de estratégias industriais coerentes com as necessidades do mercado possibilitando aos laticínios pesquisados enfrentar as ameaças dos produtos oriundos do MERCOSUL.

\section{REFERÊNCIAS}

ALVARENGA, T. H. P. et al. Gestão da qualidade na produção de alimentos: um estudo de caso no sul de Minas Gerais. Revista de Ciência e Tecnologia (UNIG), v. 12, n. 2, p. 43-53, dez. 2012.

BAPTISTA, J. R. V.; SUGAMOSTO, M.; WAVRUK, P. Características e perspectivas da indústria de laticínios do Paraná. Caderno IPARDES: Estudos e Pesquisas, v. 1, n. 1, p. 32-46, jan./jun. 2011.

BARBOSA, A. V. Uso de indicadores de desempenho nas empresas construtoras brasileiras: diagnósticos e orientações para utilização. 2010. 273f. Tese (Doutorado em Engenharia da Produção) - Universidade de São Paulo. São Carlos, 2010.

BAYO-MORIONES, A.; CERIO, J. M. D. Quality management and high performance work practices: Do they coexist? International Journal of Production Economics, v. 73 , n. 3, p. 251-259, oct. 2001.

BELIK, W. Agroindústria e reestruturação industrial no Brasil: elementos para uma avaliação. Cadernos de Ciência \& Tecnologia, v. 11, n. 1, p. 58-75, 1994.

BENNER, M. et al. Quality function deployment (QFD): can it be used to develop food products? Food Quality and Preference, v. 14, n. 4, p. 327-339, jun. 2003.

BORRÁS, M. A. A.; TOLEDO, J. C. Coordenação da qualidade: proposta de estrutura e método para cadeias de produção agroalimentares. Revista Produção, São Paulo, v. 17, n. 3, p. 471-485, set./dez. 2007.

BRASIL. Mistério da Agricultura, Pecuária e Abastecimento. Secretaria de Defesa Agropecuária. Departamento de Inspeção de Produtos de Origem Animal. Resolução no 10, de 22 de maio de 2003. Institui o Programa Genérico de Procedimentos - Padrão de Higiene Operacional - PPHO. Diário Oficial da União. Brasília, 28 de maio de 2003.

Instrução Normativa n. 51, de 20 de setembro de 2002. Aprovar

os Regulamentos Técnicos de Produção, Identidade e Qualidade do Leite tipo A, do Leite tipo B, do Leite tipo C, do Leite Pasteurizado e do Leite Cru Refrigerado e o Regulamento Técnico da Coleta de Leite Cru Refrigerado e seu Transporte a Granel, em conformidade com os Anexos a esta Instrução Normativa. Diário Oficial da União. Brasília, 21 de setembro. 2002. 
Instrução Normativa n. 62 de 29 de dezembro de 2011. Regulamento Técnico de Identidade e Qualidade de Leite Cru Refrigerado, o Regulamento Técnico de Identidade e Qualidade de Leite Pasteurizado e o Regulamento Técnico da Coleta de Leite Cru Refrigerado e seu Transporte a Granel.Diário Oficial da União. Brasília, 29 dezembro de 2011.

Portaria n. 58/93 de 17 de maio de 1993. Estabelece diretrizes e princípios para a inspeção e fiscalização sanitária de alimentos, diretrizes e orientações para o estabelecimento de padrões de identidade e qualidade de bense serviços na área de alimentos: boas práticas de produção e prestação de serviços; regulamento técnico para estabelecimento de padrões de identidade e qualidade dos alimentos. Diário Oficial da União. Brasília, 31 maio 1993.

BUENO, M. P. Gestão da qualidade nos frigoríficos de abate e processamento de frangos no Estado do Mato do Grosso do Sul. 2006. 85f. Dissertação (Mestrado em agronegócios) Universidade Federal do Mato Grosso Sul. Campo Grande, 2006.

CAMPOS, V. F. Controle da qualidade total (no estilo japonês). Belo Horizonte: Fundação Christiano Ottoni, 2004.

CARNEVALLI, J. A.; SASSI, A.; MIGUEL, P. A. C. Comparação do uso do QFD no Brasil e no Reino Unido. Produto e Produção, v. 6, n. 2, p. 31-39, jun. 2002.

CARVALHO, M. M.; Qualidade. In: BATALHA, M. O. Introdução à engenharia da produção. Rio de Janeiro: Elsevier, 2008. cap. 4, p. 53-77.

CONCHON, F. L.; LOPES, M. A. Rastreabilidade e segurança alimentar. Boletim Técnico da Universidade Federal de Lavras, n. 91, p. 1-25. 2012.

DAHMER, A. M. Avaliação da qualidade da gestão da qualidade na indústria de leite do Estado do Mato Grosso Sul. 2006. 218f. Dissertação (Mestrado em agronegócios) Universidade Federal do Mato Grosso Sul. Campo Grande, 2006.

DEMING, W. E. Qualidade: a revolução da administração. Rio de Janeiro: Saraiva, 1990.

DESANTIS, C.; ZANINELLI, M.; TANGORRA, F. M. Development of HW and SWsolutions for milk traceability. In: COMPUTERS IN AGRICULTURE AND NATURAL RESOURCES, 2006, Orlando. Proceedings... Orlando: American Society of Agricultural and Biological Engineers, 2006.

DINIZ, M. G. Desmistificando o controle estatístico de processo. São Paulo: Artliber, 2001.

ESTÁCIO, S. N. A importância do treinamento na implantação da norma ISO 9000 e como determinante da eficácia organizacional. 2003. 103 f. Dissertação. (Mestrado em Administração) - Universidade Federal de Santa Catarina. Florianópolis, 2003. 
FIGUEIREDO, V. F.; COSTA NETO, P. L. O. Implantação do HACCP na indústria de alimentos. Revista Gestão \& Produção, São Carlos. v. 8, n. 1, p. 100-111, abr. 2001.

FONSECA, P. J. P. Importância das MPE na geração de empregos em anos de crise. Boletim Estudos \& Pesquisas, UEG, SEBRAE. n. 14, nov. 2012.

FURTINI, L. L. R.; ABREU, L. R. Utilização de APPCC na indústria de alimentos. Ciência e Agrotecnologia, v. 30, n. 2, p. 358-363, mar./abr. 2006.

GARVIN, D. A. Gerenciando a qualidade: a visão estratégica e competitiva. Rio de Janeiro: Qualitymark, 2002.

GIL, A. C. Como elaborar projetos de pesquisa. São Paulo: Atlas, 2002.

GODOY, A. S. Introdução à pesquisa qualitativa e suas possibilidades. Revista de Administração de Empresas, v. 35, n. 2, p. 53-67, mar./abr. 1995.

GODOY, L. P. et al. Avaliação do grau de contribuição das normas de garantia da qualidade ISO-9000 no desempenho de empresas certificadas. Revista de Administração da UFSM, v. 2, n. 1, p. 41-58, jan./abr. 2009.

GONÇALVES, D. F.; PARRÉ, J. L. Produtividade total dos fatores para a agroindústria no estado do Paraná. Revista Economia \& Tecnologia, v. 21, n. 2, p. 57-64, abr./jun. 2010.

GOUVEIA, F. Indústria de alimentos: no caminho da inovação e de novos produtos. Inovação Uniemp, v. 2, n. 5, p. 32-37, nov./dez. 2006.

HARRIGAN, W. F. The ISO 9000 series and its implications for HACCP. Food Control, v. 4, n. 2, p. 105-111. 1993.

IPARDES - Instituto Paranaense de Desenvolvimento Econômico e Social. Caracterização da indústria de processamento e transformação do leite no Paraná - 2010.

JURAN, J. M.; GRYNA, M. Controle da qualidade handbook: conceitos, políticas e filosofia da qualidade. São Paulo: Makron Books, 1991.

LINS, B. F. E. Ferramentas básicas da qualidade. Ciência da Informação, v. 22, n. 2, p. 153-161, mai./ago. 1993.

MACHADO, R. T. M. Sinais de qualidade e rastreabilidade de alimentos: uma visão sistêmica. Organizações Rurais e Agroindustriais, v. 7, n. 2, p. 227-237, 2005.

MARCOS, S. K.; JORGE, J. T. Desenvolvimento de tomate de mesa, com o uso do método QFD (Desdobramento da Função Qualidade), comercializado em um supermercado. Horticultura Brasileira, v. 20, n. 3, p. 490-496, set. 2002.

MEIRA, A.; CERON, G. Guia digital ISO 9000. Curitiba: Domo, 2004. 
MÉLO, M. A. N. Qualidade e inteligência competitiva no setor de saúde suplementar: proposição de um modelo para a análise da estratégia competitiva. 2007. 230f. Tese (Doutorado em Engenharia da Produção) - Universidade Federal de Pernambuco. Recife, 2007.

MENDONÇA, M. M. A. R. Gestão da qualidade e gestão da informação: o caso do processo de concepção e desenvolvimento de uma PME de base tecnológica. 2008. 65f. Dissertação (Mestrado em Engenharia Electrotécnica e de Computadores Major Automação) - Universidade do Porto. Porto, 2008.

MIGUEL, A. C. A. et al. Aplicação do método QFD na avaliação do perfil do consumidor de abacaxi "pérola". Ciência Agrotecnologia, v. 31, n. 2, p. 563-569, mar./abr. 2007.

MONTEIRO, S. B. S. Coordenação da qualidade em cadeias de produção de alimentos: práticas adotadas por grandes empresas. 2005. 217f. Tese (Doutorado em Engenharia da Produção) - Universidade Federal de São Carlos. São Carlos, 2005.

MONTGOMERY, D. C. Introdução ao controle estatístico de qualidade. Rio de Janeiro: LTC, 2009.

OLIVEIRA, C. A. F. et al. Avaliação dos custos envolvidos na implementação de BPF e APPCC em uma indústria de laticínios de pequeno porte. Veterinária e Zootecnia, v. 20 , n. 1, p. 38-39, mar. 2013.

OTOBONI, J.; FERNANDES, T. Rastreabilidade pode ser a saída para o leite. Veja On-line, 27 mai. $2013 . \quad$ Disponível em:http://veja.abril.com.br/economia/rastreabilidade-pode-ser-a-saida-para-o-leite.

Acesso em: 14 out. 2013.

PALADINI, E. P. Gestão estratégica da qualidade: princípios, métodos e processos. São Paulo: Atlas, 2008.

PASCHE, I. M.; FERREIRA, G. M. V. Gestão da qualidade nas agroindústrias: um estudo exploratório no município de Marau-RS. Extensão Rural, Santa Maria, n. 20, p. 49-79, jul./dez. 2010. Disponível em: https://periodicos.ufsm.br/extensaorural/article/view/5550/3275. Acesso em 15 set. 2017.

PINTO, A. L. D.; PAIVA, C. L. Desenvolvimento de uma massa funcional pronta para tortas utilizando o método de Desdobramento da Função Qualidade (QFD). Ciência e Tecnologia de Alimentos, v. 30, n. 1, p. 36-43, mai. 2010.

PINTO, S. H. B.; CARVALHO, M. M.; HO, L. L. Implementação de programas de qualidade: um survey em empresas de grande porte no Brasil. Gestão \& Produção,v. 13, n. 2, p.191-203, maio/ago. 2006.

QUEIROZ, S. H. Motivação dos quadros operacionais para a qualidade sob o enfoque da Liderança Situacional. 1996. 157f. Dissertação (Mestrado em Engenharia de Produção) - Universidade Federal de Santa Catarina, Florianópolis, 1996. 
REZENDE, C. F.; ANDRADE, D. M, J.; REZENDE, D. C. O processo de sucessão em empresas familiares: um estudo de caso no ramo de laticínios no sul de Minas Gerais. Organizações Rurais e Agroindustriais, v. 6, n. 1, p. 107-118, jan./jun. 2004.

ROBIM, M. S. Pesquisa de fraude no leite UAT integral comercializado no estado do Rio de Janeiro e comparação entre os métodos de analises fisicoquímicas oficiais e o método de ultrassom. Revista Instituto de Laticínios Cândido Tostes, v. 389, n. 67, p. 43-50, 2012.

RUIZ, J. A. Metodologia científica: guia para eficiência nos estudos. São Paulo: Atlas, 1996.

SANTOS, A. B.; ANTONELLI, S. C. Aplicação da abordagem estatística no contexto da gestão da qualidade: uma survey com indústrias de alimentos de São Paulo. Gestão \& Produção, v. 18, n. 3, p. 509-524. 2011.

SANTOS, I. M.; MEDEIROS, D. D. Adição de uma nova perspectiva ao BSC para avaliar o SGQ em empresas de serviços certificadas com a norma ISO 9001:2000.

Revista Gestão Industrial, v. 4, n. 2, p. 17-33. 2008.

SCALCO, A. R. Estratégias e tendências da agroindústria de laticínios brasileira. In: ENCONTRO NACIONAL DE ENGENHARIA DA PRODUÇÃO, 17, 1998, Niterói. Anais eletrônicos... Rio de Janeiro: ABEPRO, 1998. Disponível em: http://www.abepro.org.br/biblioteca/ENEGEP1998_ART178.pdf. Acesso em: 15 mar. 2012.

SCALCO, A. R. Proposição de um modelo de referência para gestão da qualidade na cadeia de leite e derivados. 2004. 225f. Tese (Doutorado em Engenharia da Produção) - Universidade Federal de São Carlos. São Carlos, 2004.

SCALCO, A. R.; TOLEDO, J. C. Gestão da qualidade em laticínios do estado de São Paulo: situação atual e recomendações. RAUSP, v. 37, n. 2, p. 17-25, abr./jun. 2002.

SEBRAE (Serviço Brasileiro de Apoio às Micro e Pequenas Empresas). Fatores condicionantes e taxa de mortalidade de empresas no Brasil. Relatório de pesquisa. Brasília. 2004.

SEBRAE (Serviço Brasileiro de Apoio às Micro e Pequenas Empresas). Sobrevivência e mortalidade das MPE. Fatores condicionantes. 2007.

SILVA, C. E. S.; GONÇALVES, T. C. C. Proposta de utilização do Quality Function Deployment (QFD) no sistema de análise de pontos críticos de controle (APPCC) na produção de refeições. Revista GEPROS, v. 1, n. 3, p. 113-123, ago. 2006.

SLACK, N. et al. Administração da produção. São Paulo: Atlas, 2009.

SOUZA, C. C. et al. A percepção de compradores sobre a qualidade da carne suína in natura no mercado varejista de Campo Grande (MS). Extensão Rural, Santa Maria, v. 23, n. 3, p. 151-168, jul./set. 2016. Disponível em: 
<https://periodicos.ufsm.br/extensaorural/article/view/21488/pdf>. Acesso em: 15 set. 2017.

SPEXOTO, A. A.; OliVEIRA, C. A. F.; OLIVAL, A. A. Aplicação do sistema de análise de perigos e pontos críticos de controle em propriedade leiteira tipo $A$. Ciência Rural, v. 35, n. 6, p.1424-1430, nov./dez., 2005.

TOLEDO, J. C.; BATALHA, M. O.; AMARAL, D. C. Qualidade na indústria agroalimentar: situação atual e perspectivas. Revista de Administração de Empresas - RAE, v. 40, n. 2, p. 90-101, abr./jun. 2000.

UEPG - Universidade Estadual de Ponta Grossa. Dicionário Histórico e Geográfico dos Campos Gerais. Disponível em: http://www.uepg.br/dicion/campos_gerais.htm. Acesso em: 15 jan. 2014.

VILELA, N. J.; MACEDO, M. M. C. Fluxo de poder no agronegócio: o caso das hortaliças. Horticultura Brasileira, v. 18, n. 2, p. 88-94, jul. 2000.

VINHOLIS, M. M. B.; AZEVEDO, P. F. Segurança do alimento e rastreabilidade: o caso BSE. Revista de Administração de Empresas - RAE, v.1, n. 2, jul./dez. 2002. 